\title{
THE CONTROVERSY OF ROOTING AND CONTRASTING ONE-LETTER FORMATIONS
}

\author{
Kifah Jumaah Hafth SABER ${ }^{1}$
}

\section{Istanbul / Türkiye \\ p. 201-216}

Received: $29 / 11 / 2021$

Accepted: 08/12/2021

Published: 01/01/2022

This article has been scanned $t$

iThenticat No plagiarism detected

\begin{abstract}
:
The concept of rooting and renewal in Arabic calligraphy is linked to the calligrapher's need to show new aesthetic methods, through formations and calligraphic structures based on a single letter. The perceptual vision of the calligrapher, so this research was concerned with studying the rooting and renewal of the rule of the single letter in the formations of Arabic calligraphy in particular, which included four chapters, the first chapter included the research problem, its importance, objectives, limits and definition of its terms.

As for the second chapter, it deals with tracing the concept of rooting and renewal and its connection with the artist and the possession of the idea and the ability to technical aesthetic expression, through the one-letter linear formations made by calligraphers, relying on the spatial organization and choosing the appropriate letter for the composition.

The analysis concluded with a number of results that were devoted to the fourth chapter, which showed rooting, renewal, acceptance of decorative and different aesthetic formations in structural structures, and investing some characteristics of letters to arrange and divide the linear structure into creative forms and structures.
\end{abstract}

Key words: Contrasting, Formations, Renewal. 


\section{جدل التأصيل والمغايرة في تكوينات الحرف الواحد}

\section{كفاح جمعة حافظ صبر 2}

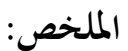

أرتبط مفهوم التأصيل والتجديد في الخط العربي بحاجة الفنان الخطاط إلى إظهار أساليب جمالية جديدة، من خلال التكوينات والتراكيب الخطية المبتكرة المعتمدة على الحرف الواحد، وقد ساعدتها بعض الخصائص الفنية

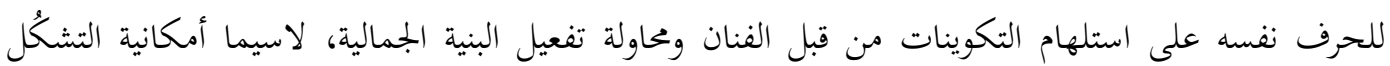
والتحكم بالحروف وتوسع الرؤية الإدراكية للخطاط، لذا عني هذا البحث بدراسة التأصيل والتجديد لسيادة

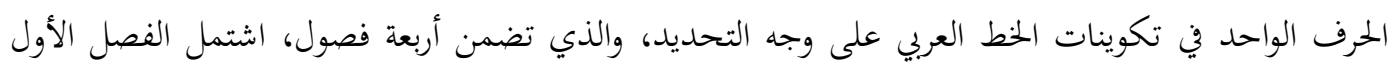

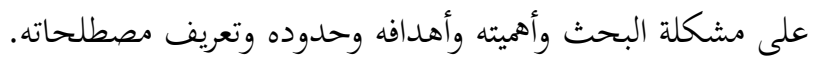

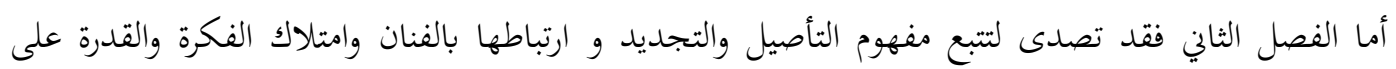
التعبير الجمالي التقني، من خلال التكوينات الخطية ذات الحرف الواحد التي قام بها الخطاطين، باعتماده على التنظيم المكاني واختيار الحرف المناسب للتكوين. أما الفصل الثالث فقد مثل إجراءات البحث وبجتمعه الذي بلغ (20) تكويناً معتمداً على الحرف الواحدا، اختير منها (2) نموذجاً لتمثيل المجتمع والتي اعتمد فيها الباحث على المنهج الوصفي التحليلي على وفق المنهج العلمي.

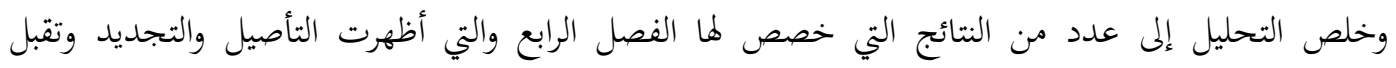
التكوينات الجمالية الزخرفية والمغايرة في البنى التركيبة واستثمار بعض خصائص الحروف لترتيب وتقسيم التركيب

$$
\text { الخطي إلى أشكال وبنى إبداعية. }
$$

الكلمات المفتاحية: جدل التأصيل، المغايرة، تكوينات الحرف الواحدي، إندال

المغايرة والتأصيل في التقليد والمحاكاة مفهومان متناقضان كلياً، فالتقيد عُد قاعدة سار عليها طلاب الخط العربي على

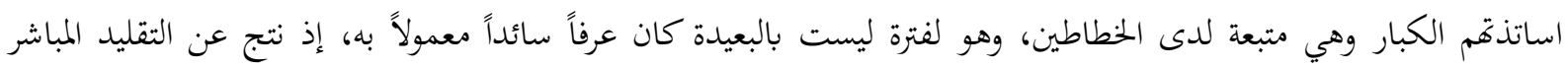

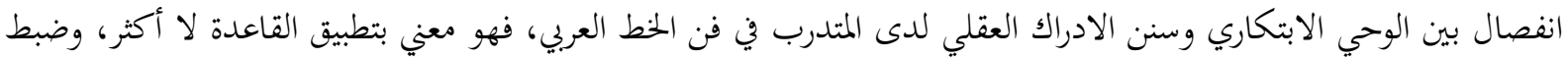
حروفها بشكل تطابقي مع الاستاذ أو المدرب، وهي صفة ليست ذميمة، بالعكس كان كبار الخطاطين المجودين يتبارون في تقليد

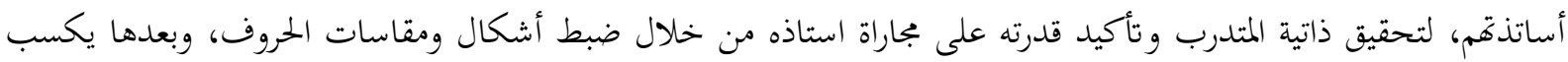

$$
\text { رضا استاذه فيجيزه ضمن العرف المعمول به تقليدياً. }
$$

والتجديد والتأصيل يبدوان مصطلحان متضادان في المعنى بشكل كامل، إلا ان الوقت الحاضر وبعد كل هذه النتاجات

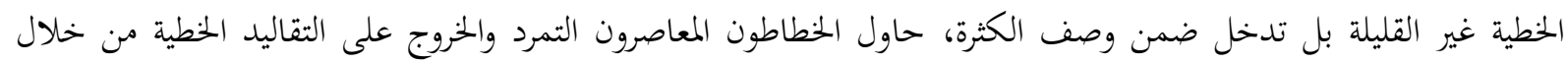

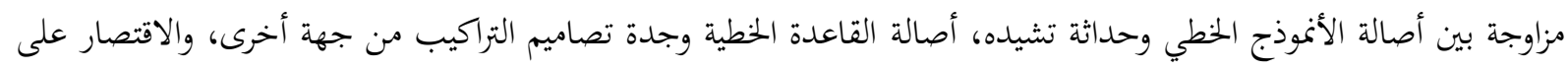

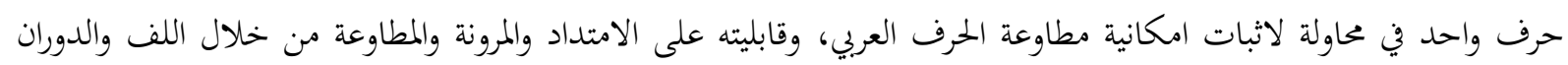


والصعود والنزول والاستطالة والمد وغيرها من الصفات التي يتمتع بها دون الخروج عن الأصالة في القاعدة الجمالية والهندسية،

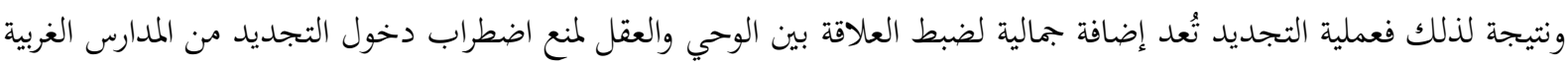

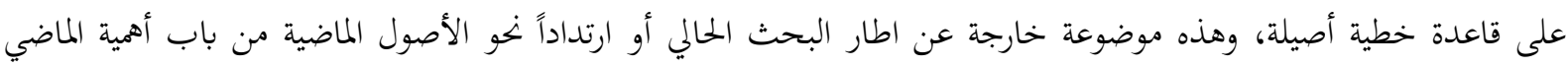

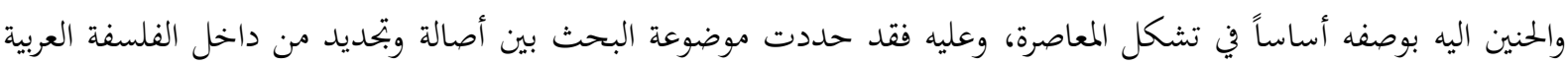
الاسلامية والعرف الخطي المتأصل مع التحرر ضمن معطيات المرحلة. 


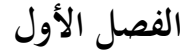

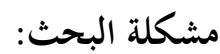

يُعد الخط العربي أحد الانجازات الجمالية التي تحتضن فاعلية الإبداع ومفصلاً مهماً من خلال المنجزات الخطية المتقنة، فهو

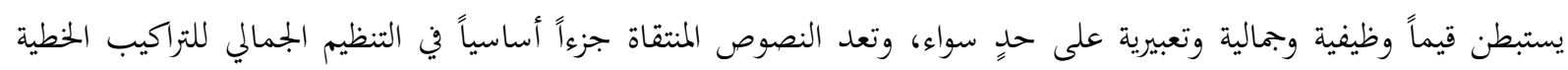

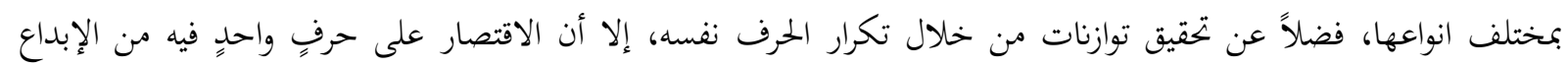

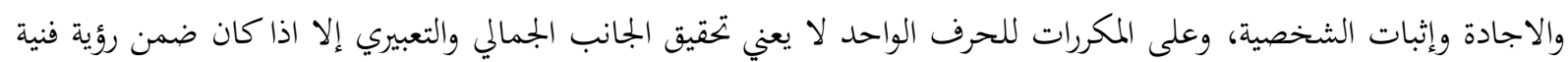

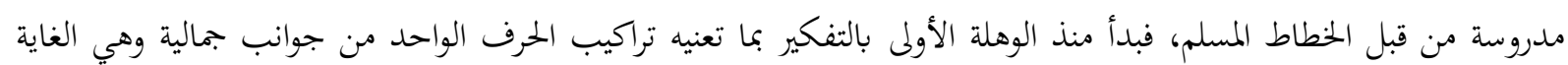
الأساسية وتعبيرية ان وجدت فئل الخطات

فظهر الجانب الجمالي والتعبيري للخط العربي من خلال تكرار رسم الحرف الواحد و معالجة الفضاءات البينية داخل البناء

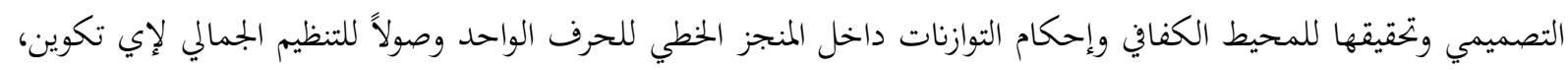

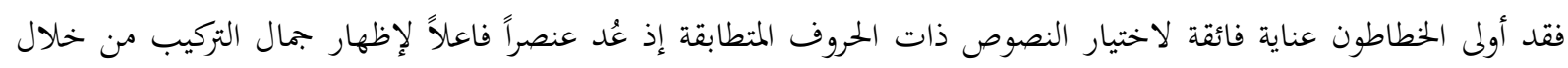

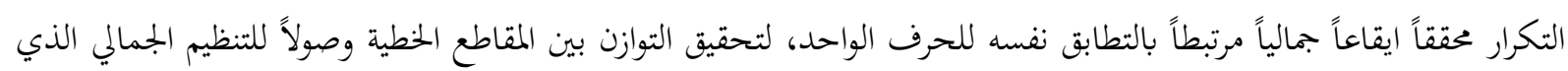

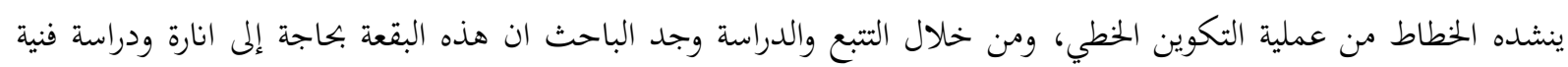
أكاديمية وعليه صاغ مشكلة بحثه بالتساؤل الاتي:

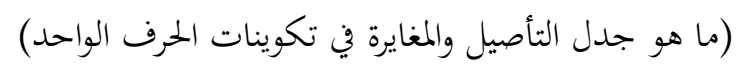

\section{أهمية البحث والحاجة اليه:}

1- يسهم البحث الحالي في تحديد جماليات التأصيل والمغايرة في ايقاع الحرف المتطابق الواحد وأسباب التطابق الشكلي له في تكوينات الخط العربي وصولاً للتنظيم الجمالي والتعبيري. 2- يسلط البحث الضوء على موضوعة مهمة مرتبطة بين الخط العربي قاعدياً وجمالية المنجز البصري المتمثل بالتكوينات الخطية، فضلاً عن إمكانية الإفادة من نتائج البحث في تعزيز الجوانب الفكرية والتطبيقية لدى المعنيين بميدان الخط العربي عموماً. 3- مرونة وطلاقة الحرف العربي وقابليته على التجدد والانتشار ضمن قاعدة تناسبية جمالية.

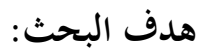

كشف التأصيل المغايرة للتكوينات المعتمدة على الحرف الواحد في الخط العربي، وأسسها التنظيمية المتبعة وصولاً للتنظيم

$$
\text { الجمالي داخل التراكيب الخطية وارتباطها بمعانيها. }
$$

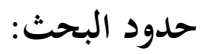

1.الحد الموضوعي: التكوينات الجمالية المتقنة المعتمدة على الحرف الواحد في خط الثلث الجلي على خامة الورق.

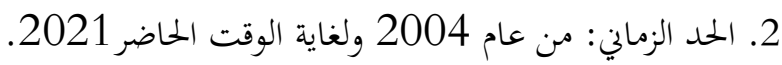

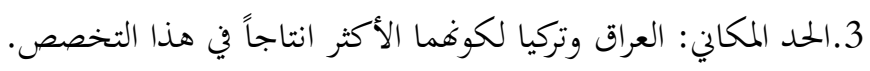


1. (عرف الباحث المطلح لأنه جديد ويخص موضوعة البحث اجرائياً)

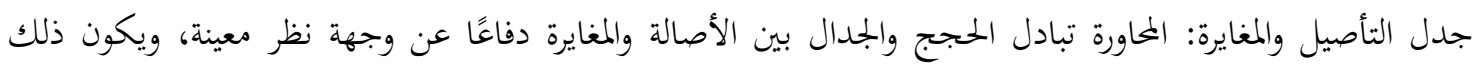

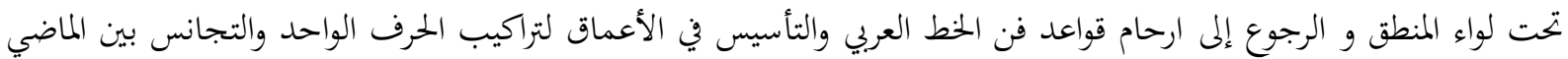
والحاضر فكل بتديد بلا أساس يكون غير مستقر فنياً، لتجنب الازدواجية بين أنصار الأصالة وأنصار التجديد في فن الخط العربي، وبهذا المغايرة تكون شرط الأصالة.

2. المغايرة: وجود اختلاف في البجال المرئي (جيلام،1980،ص15)

هو نوع من المقارنة بين الاختلافات التي تظهر في هيأتين أو أكثر ومختلفة فينة في جوانب أخرى

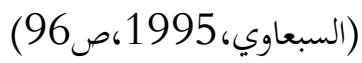

المغايرة إجرائياً: المزج بين القديم والجديد في هيأة بصرية تحتكم إلى معايير وقواعد جمالية أصيلة، مرتبطة بالتجديد ضمن رؤى فلسفية. 3. تكوينات الحرف الواحد: التراكيب المعتمدة في بِنيتها الشكلية على تطابق وتكرار حرفاً واحداً، لتحقيق التجديد ضمن رؤية فنية حديثة، مستعيناً بخصائص الحروف التصميمية لتحقيق ذلك. 


\section{تأصيل القاعدة في تكوينات الحرف الواحد}

التأصيل في الخط العربي هو بيان الأصل من قواعده و إتباع طريقة الاساتذة من المجودين القداما، والذين ساروا على هذا

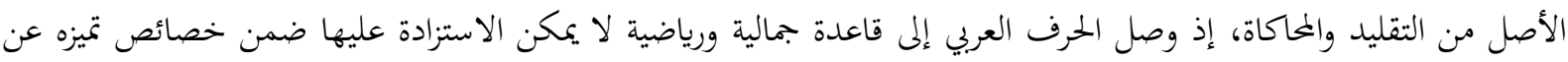
غيره وهو ما ينفرد به الثكل (الحرف أو الكلمة) من صفات بارزة تحدد كينونته وتدل عليه محددة معالمه بما تفرقه عن غيره وبتعل

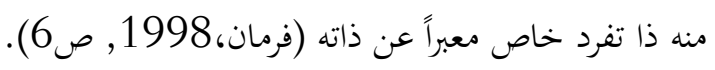

فبينما يصر بعض الخطاطين على ضرورة المحافظة عليها واستبعاد اي ممارسة بتحيدية قد تضر بشكل الحرف العربي، إلا ان ان

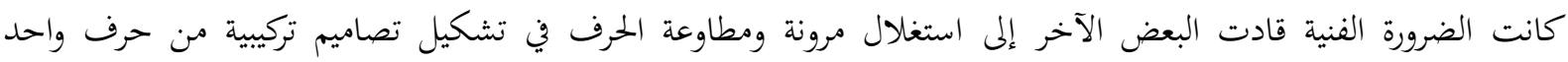

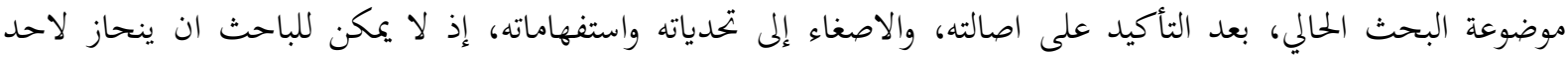
الموقفين ويسبغ عليه المشروعية، ومن الاجدر ان نبحث وبدقة متناهية عن بواعث كل موقف وتداعياته ومنطلقاته، وهنا تبرز

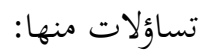
1. للتجديد دوراً جمالياً في اغناء التأصيل ضمن فلسفة جمالية مختلفة تتواكب ومعطيات العصر في تكوينات الحرف الواحد دون نصاً محدداً ام خلاف ذلك. 2. هناك تقاطع سلبي بينهما، اي اضافة المغايرة تضر بالأصالة التناسبية لقاعدة الحرف الواحد أو تفيده جمالياً، وما سبب غزارة الانتاج فيه.

3. القواعد والمعايير تنطبق عليهما في اي زمن، ام تتحدد بالرؤى الفلسفية المتجددة.

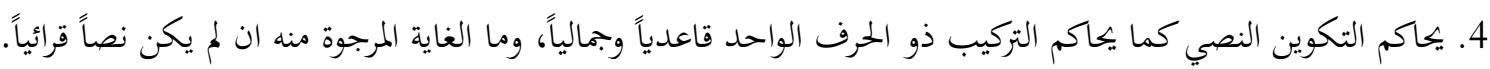

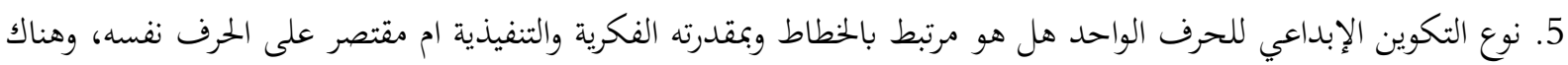
تباين في تجارب الفنانين في الخط العربي. فمنهم من يفهم التجديد بالاغتراب الفكري بعد اتصال الفنان بالغرب، وتأثر أغلب الفنون التشكلية بذلك، وتشبع

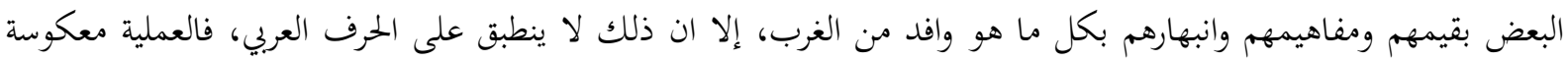

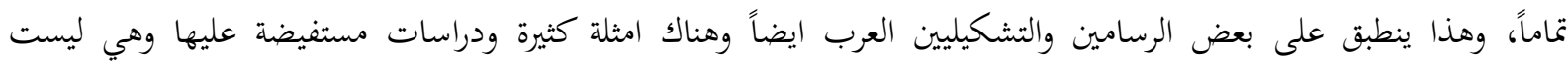

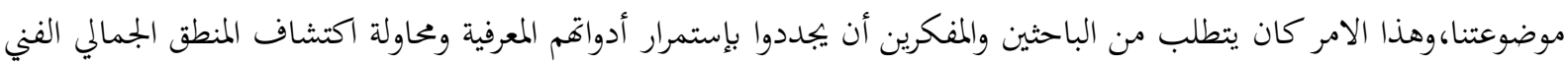

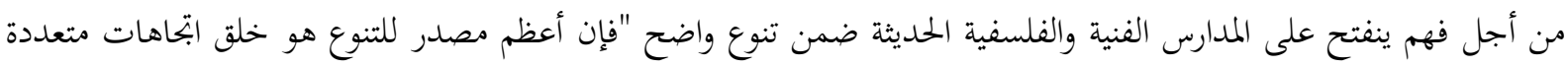

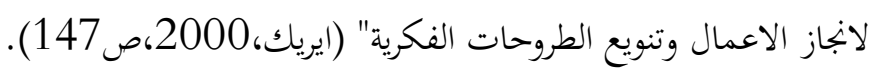

ويواكب تطورها المستمر والتفاعل مع عناصرها الايجابية وإعادة صياغتها في أطر خلفيتهم الفكرية وثوابتها الفنية والجمالية على حدٍ سواء، على عكسه عندما يتوقف ويتعطل الفكر عن التجديد وأدواته المعرفية في الخط العربي وتنشط الذاكرة والتقليد الصارم، والتأكيد على الوقوف عند قاعدة الحروف والسير على فج الاقدمين دون الخروج عن عباءقم المعتادة اعتزازاً بتراثهم الفني

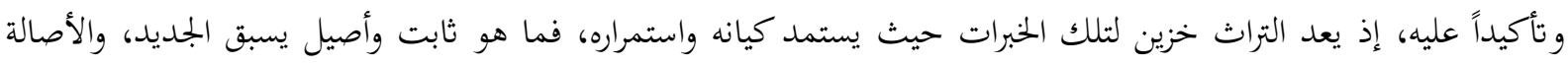
أساس المعاصرة والوسيلة تؤدي إلى الغاية (حنفي، 1987، صنائس 11) فهو يؤدي إلى السكون وفقدان الثقة بالذات والتبعية الصارمة للاساتذة على طلابهم من خلال التقليد والمحاكاة. 
ثََمة حقيقة ان بجموعة من الأقدمين تقاطعت أرائهم مع المغايرة وأخفت الوجه المشرق له حتى صار يشار له بدلالات غير

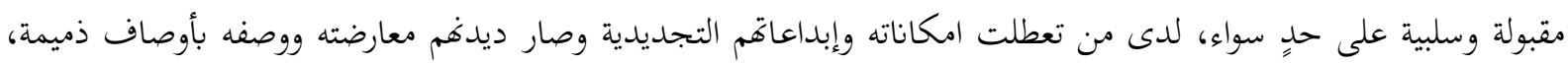

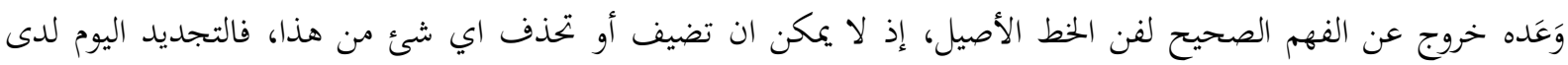

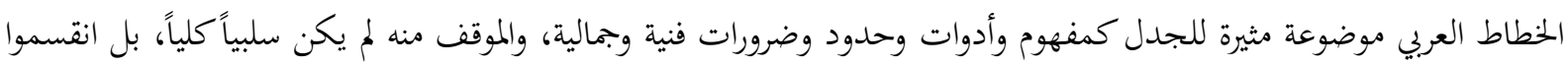

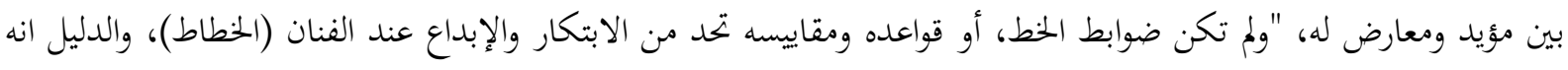

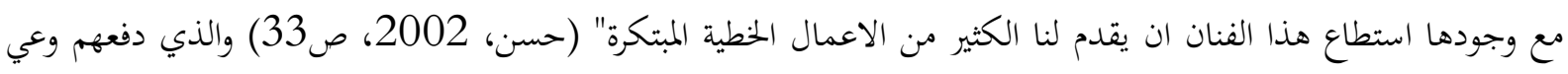

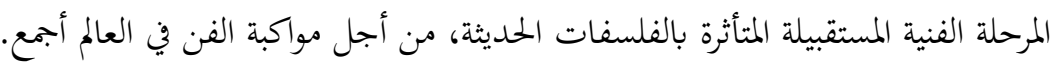

فالقيم الخطية الفنية تتحقق من خلال ترتيب العناصر والمفردات المتمثلة بالحرف العربي الواحد، في البنية الخطية دوراً جمالياً

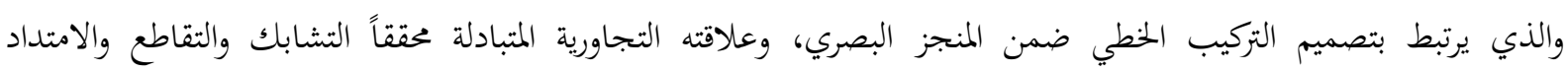
والاستطالة والتقصير ان لزم الامر، وهي تمثل الهدف الجمالي والوظيفي بعد تصميمه الذي يمتوي ذاتية وفردية الخطاط المجود، فلكل

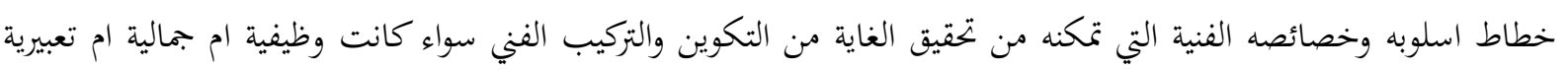
فالاسلوب "إنه طريقة صياغة الشكل وعملية تنظيم هذه القوالب التي يصب فيها الشكل، وطريقة صياغة تراكيب الأشكال التي

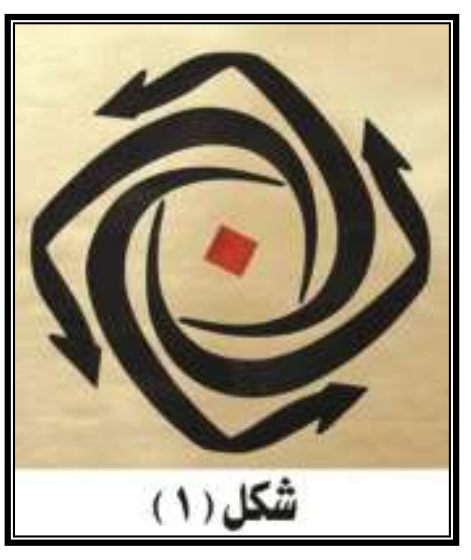

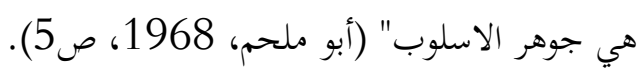

وهذا قد يجبر الخطاطين الذين يسيرون في تدريباتم على كبار الخطاطين في تطبيق النسبة الفاضلة دون ان يشعر لانه مدرب بشكل صارم وبشكل فطري وتلقائي، إذ لا يوجد تعارض بينهما أو بين الإحساس والذوق الفطري بالجمال والتفكير التناسبي

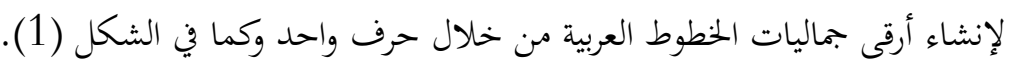
وهنا ظهر مجموعة من الخطاطين المبدعين الذين توغلوا في الممنوع والمحذر منه ألمانه

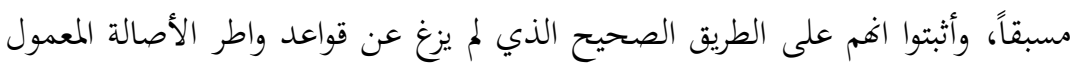
كها لدى المجودين الاقدمين.

وفي ضوء ذلك نرى أن أغلب فلاسفة العصر قد اشاروا إلى أهمية ما هو ثابت ومستقر في الحياة، كون المستقبل ليس

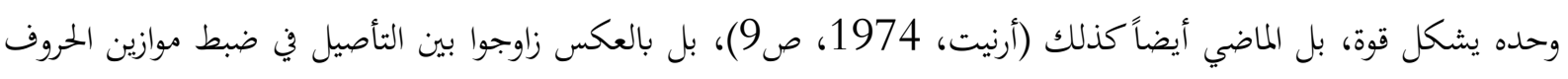
وقياساتما وجمالها الشكلي المتمثل بالمحاكاة والتقليد للحرف الواحد، وبين إبداعهم في الابتكار والتصميم من خلال خلال خلق تراكيب

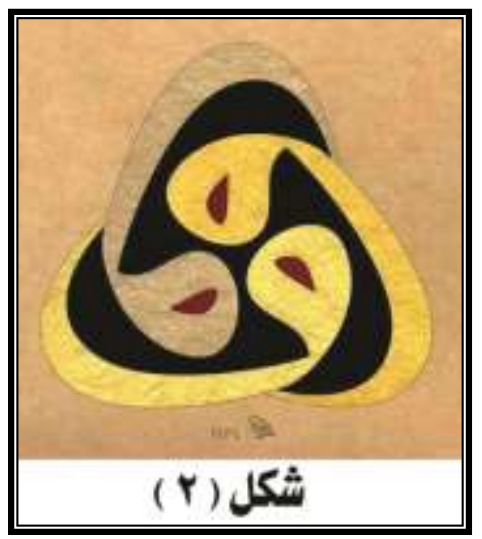
تصميمية جديدة تدخل ضمن أطر الحداثة والتجديد. وبهذا فقد باغتوا الواقع المقفل وفتحوا أبواب الإبداع ومزجوا بين الأصيل والحديث،

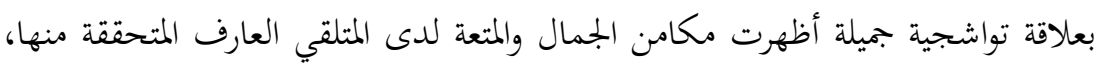
وكما في الشكل (2)

غير أن هناك بعض التكوينات لم تحقق ذلك نتيجة التشابك والتعقيد في اختيار التراكيب الفنية أو لضعف امكانية الخطاط الفنية نفسه، وعدم درايته لأصول وقواعد الخط العربي من جهة، وضعف معرفته بالتصميم والتركيب من جهة أخرى، وهذا لا يدخل

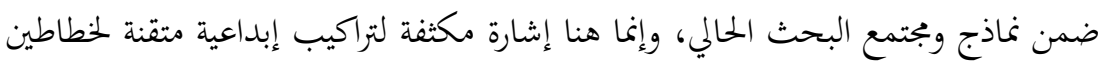
معاصرين محترفين وبجودين استغلوا حرفٍ واحٍِ وأسسوا عليه تركيبهم. 
فقد ظهر الإيقاع الخطي بشكل واضح نتيجة التكرار، لان التركيب اصلاً مبني على حرفاً واحداً وهذه من أكثر صفاة

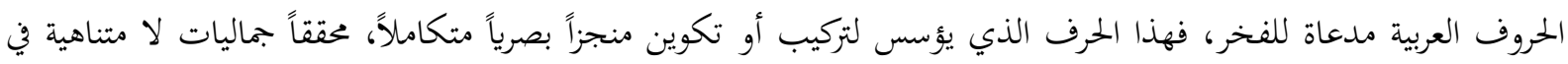
حركة تصميمية بتحيدية مبتكرة.

فعندما نراجع وندقق في التراكيب الخطية المتقنة بحثاً عن عوامل نجاحها، سيتمثل أمامنا دور الوعي الفني لدى الخطاط في

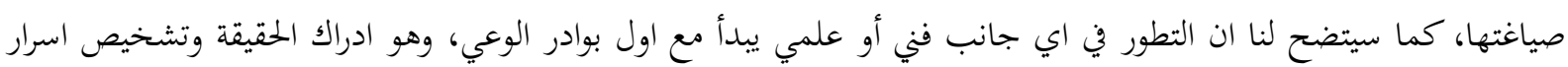
النجاح الفنية،

فالفنان الواعي مستبصر ومكتشف يقض بعيداً عن الجمود والمحدودية والتقليد الاعمى، اضافة إلى تضخيم الذات والشعور بالفوقية نتيجة ضبطه لقواعد الحروف وامكانية الخط بشكل متقن تقليدي، والانعزال والانغلاق والتقوقع ضناً منه وصوله إلى قمة ولئ الهرم والنجاح. فالفنان الواعي لا يتهيب المحذور والممنوع في الفن، ضمن تخصصه الفني، انما يتوغل في الشك والتساؤل حتى يصل لغايته ويفهم الحقائق، فهو مرهف الحس قلق متوثب يصغي دائماً ليدرك ويناقش ليفهم ولا يشتغل إلاعن قناعة ورؤية واضحة.

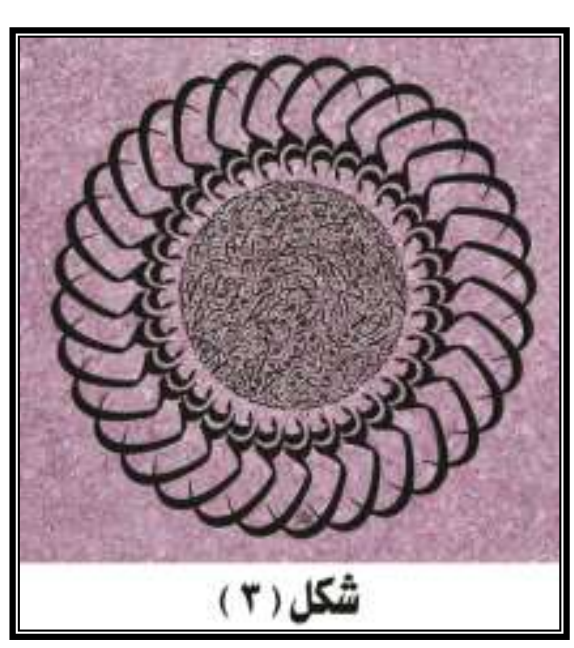

وقد بتسدت من خلال اعماله الفنية في تراكيب إبداعية متقنة بين

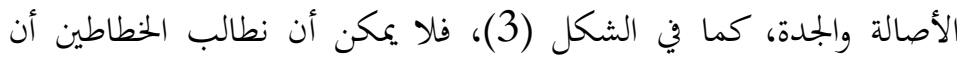
يسيروا على فه معين بالاكراه، لان المنهج نتاج الثقافة الفنية اياً كان البحاهها،

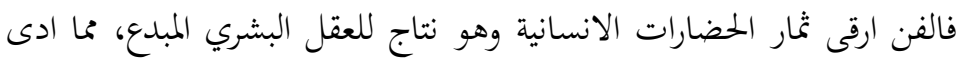
إلى ظهور مدارس ومناهج متعددة قاطعت وخالفت سابقتها وازاحتها نتيجة

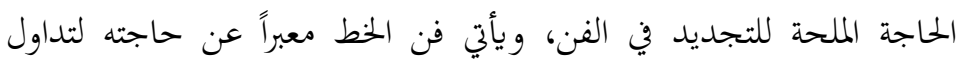

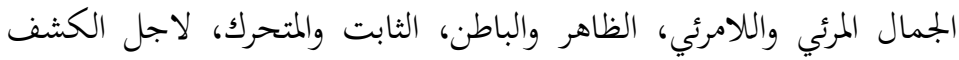
عن اهم المعايير التي يمكن الركون اليها في فن الخط العربي والتي عرفت

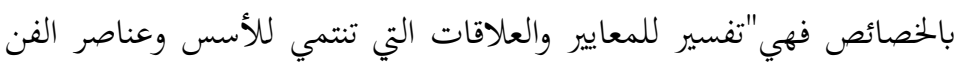

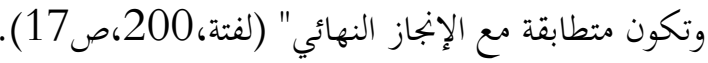
فكان منها ما اتفق مع فكرة التجديد والانفتاح واختلف البعض الاخر، وبهذا فأن فن الخط العربي يؤشر خصوصيته الفنية وفقاً إلى عملية الاستقراء الفلسفي والنظري ضمن المعطيات التي تحيط به، كما ينبغي قراءة التراث الخطي بعد توافر أدواته وفهمه وهنه وهضمه، لاجل استقراء التجديد دون انقطاع عن جذره" فما هو ثابت وأصيل يسبق الجديد، والأصالة أساس المعاصرة والوسيلة

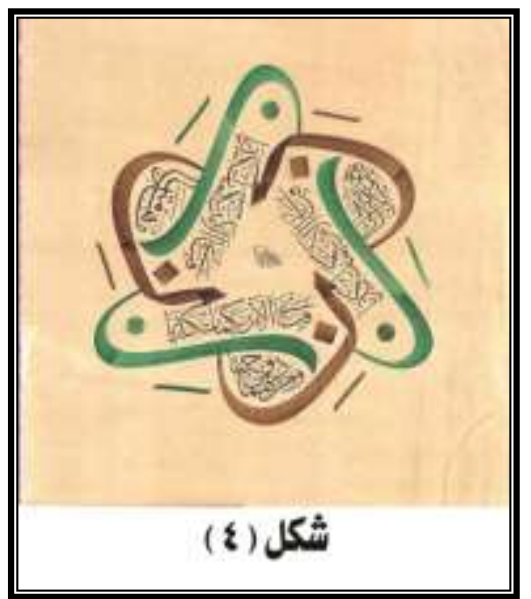

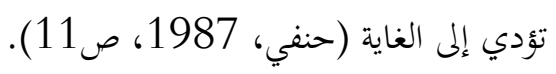

وهذا تحقق بضبط كتابة الحرف العربي جمالياً ضمن رؤية تصميمية جديدة

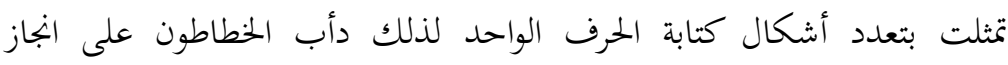

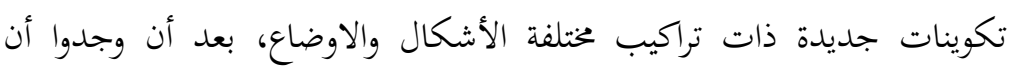
الصفات الفنية لهذه الحروف تساعد على امكانية تشكيلها، لرشاقتها وتعدد أشكالها، وتتميز بالمرونة والمطاوعة، وتتقبل المد والاستطالة والقصر بسهولة، اذهاذ

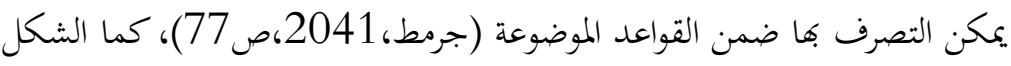


فالفنان المبدع مبادر إلى قراءة الفن قراءة معاصرة، تنسجم مع الواقع وتستجيب لحاجاته ومتطلباته، وأن يهذر التراجع

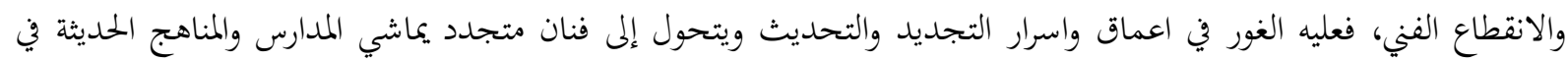

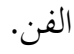

كما هو الحال في باقي الفنون الأخرى، فالخط العربي جزءً لا ينفصل عنها مع المحافظة على التأصيل، فهو بذلك يتحول

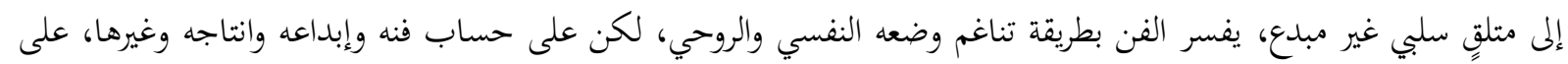

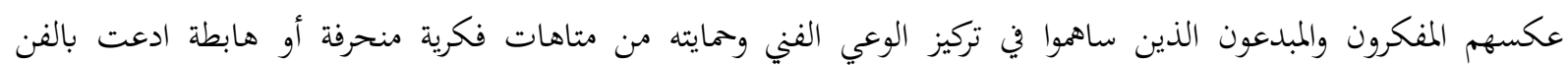
والتجديد لكنها فشلت نتيجة عدم معرفتهم لقواعد واصول الخط العربي والتي هي جزءاً لا يتجزأ من التجديد. فكل بتحيد يبنى على تأصيل وهو حاله متميزة من النشاط الانساني يترتب عليها إنتاج جديد يتميز بالجدة والأصالة، وهو

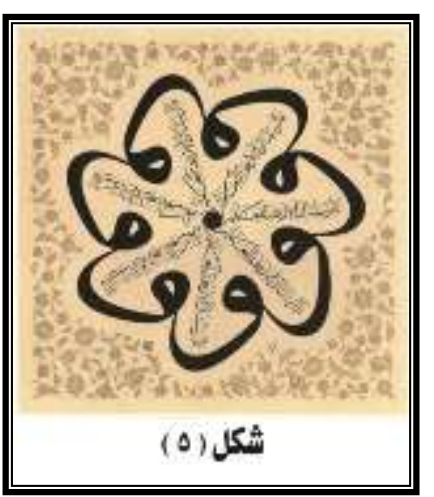

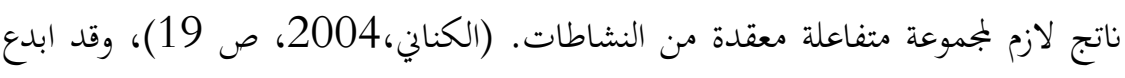
الفنان العربي في ابتكار تراكيباً خطية متنوعة متقنة ولدت بحرفٍ واحدٍ منطلقة في فضاءها

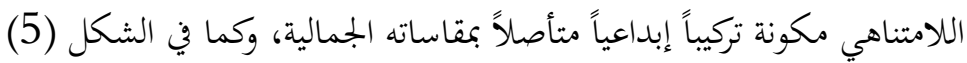
وهنا يتجسد دور الوعي الفني في تشخيص المنهج الصحيح، فالفنان الواعي المبدع لا تؤثر فيه اي بتحارب غير صحيحة، ولا المناخات الفنية السلبية، ولا يتشوه بصره في الانجازات البصرية الهابطة، وغير المتقنة والتي هي بعيدة عن الأصالة وضبط القاعدة الجمالية والهندسية

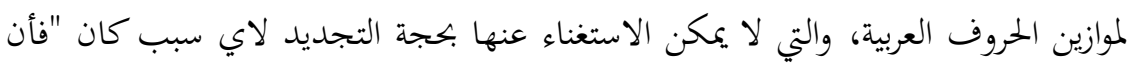

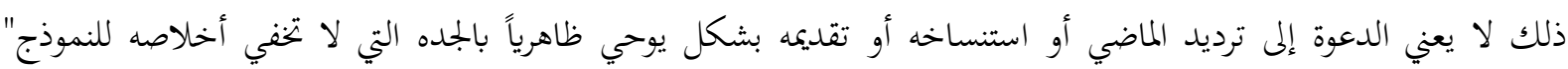

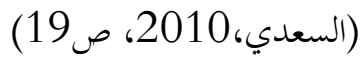

فالفنان يحتاج إلى خطاب ثقافي فني يطور وعيه إلى مستوى القبول بالرأي الاخر، والسماح بمراجعة الافكار والمفاهيم الفنية لاها قد تشيخ وتستوجب استبدالها، فالأصيل من القديم يحتاج إلى رؤية جديدة تنهض به ليواكب التطور ويتماشى مع طروحات

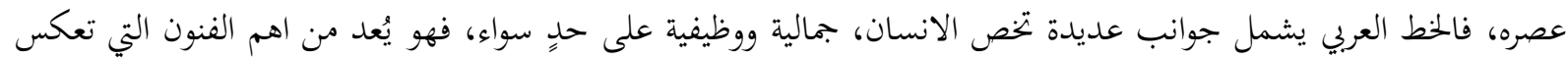

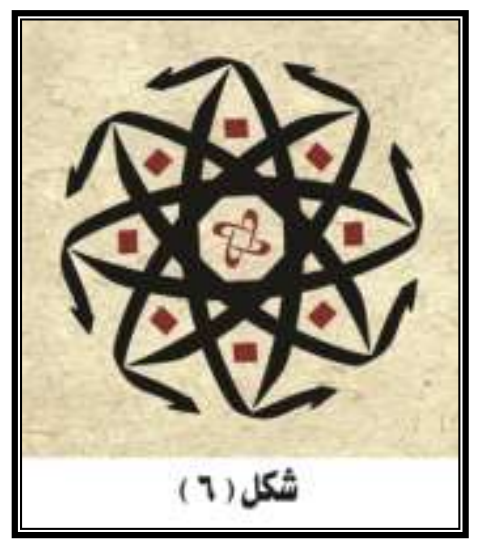
رؤيا وفكر الانسان في دراسات متعددة حديثة، لغوية وتأريخية ومنطقية وتشكلية ودراسة

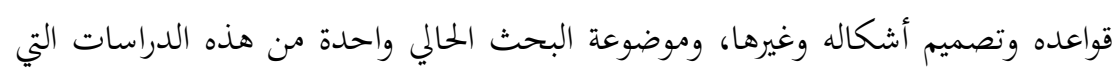

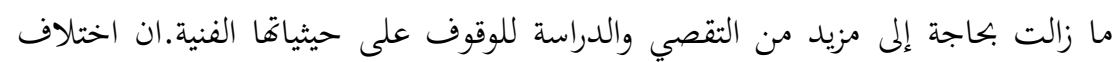
الرؤيا الجمالية للخط العربي بين دعاة الأصالة ودعاة التجديد، تتعدد معايير القياس بينهما.

فلا يمكن قياس المعايير الجمالية لديهم بنفس المقياس، ولكن يمكن الدعوة إلى المزاوجة بينهما وهذا ما هو حاصل في نماذج البحث المنتقاة بشكل قصدي، وكما في

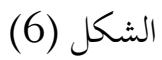

ان من اهم المفاهيم التي يبنى عليها الخط العربي هي موضوعة التأصيل، فهي موضوعة متوارثة، وهي امتداد الماضي إلى المستقبل مروراً بالحاضر، وهذه الطريقة التي يحافظ بها الخطاط المجود على قواعد واصول الخط العربي، وهذه لا تتحقق إلا بالمثابرة والاخلاص لتحقيق الاتقان في المحافظة على جمالية الخط العربي، وهي غاية كبرى للفنان أو الخطاط. 


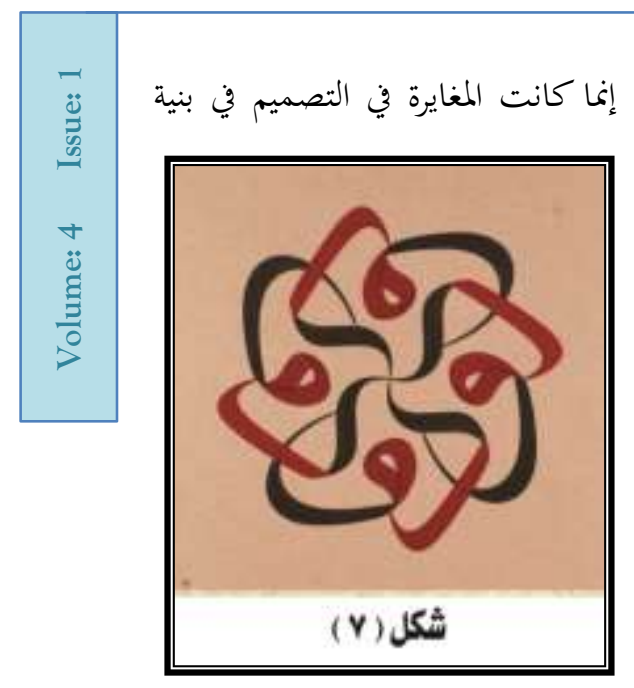

ولكن لا يمكن له حذف أو اضافة خطوط جديدة، وفق رؤية حديثة بتحيدية، التراكيب وأشكاله المتباينة، هي الميدان الاوسع لإظهار أمكانياته ضمن رؤية بتحيدية

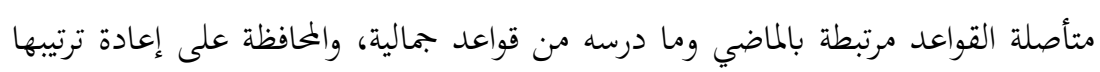

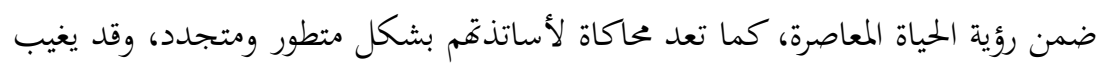
الموضوع في التركيب للحرف الواحد، ويكتفي المصمم الخطاط بتحقيق الجانب الجمالي

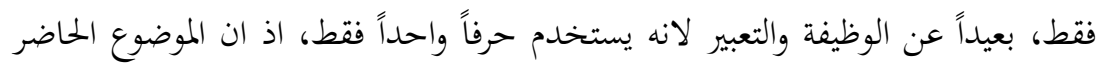

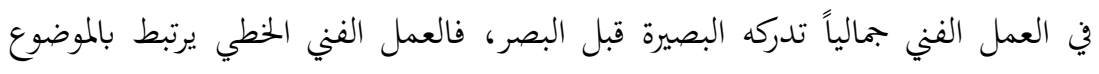

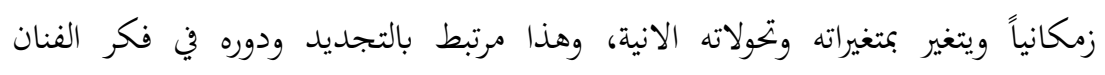

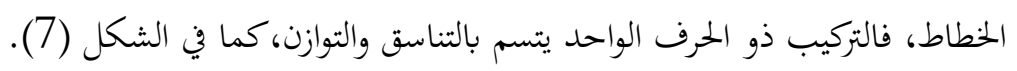
جذاب المنظر يسر الرؤيا لدى المتلقي لما يمتلكة من انتظام وترديد في شكل الحرف الواحد، متناغم ومتوافق وتكون الوحدة

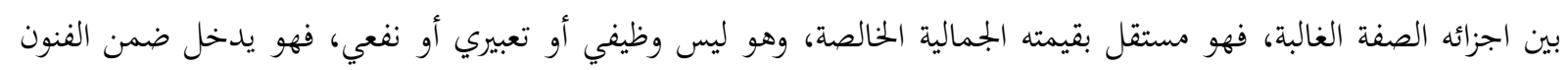

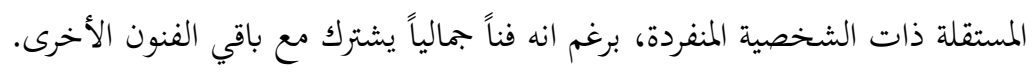
وهنا يجب الإشارة إلى ان نقاط الخلاف بين دعاة التأصيل ودعاة التجديد المتعددة، تشكل قيوداً ومعرقلاً على عملية

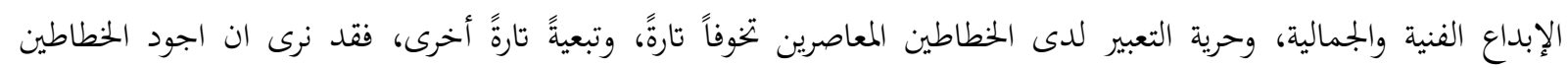

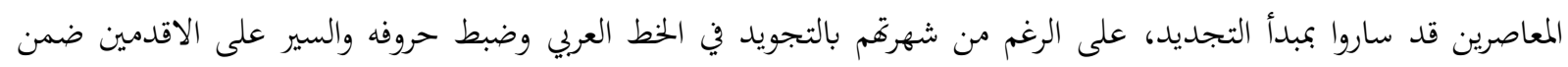

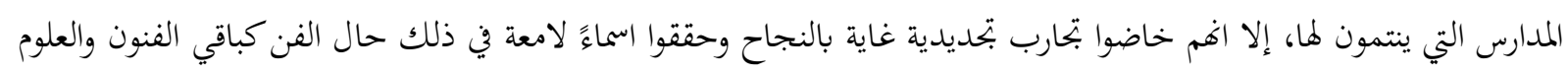
الأخرى.

المبحث الثاني

\section{مسارات التحديث في تكوينات الحرف الواحد}

إتخذت مسارات تحديث التكوينات الخطية المعاصرة شكلاً جديداً في تصيرها تبعاً للمتغيرات الخارجية التي جاء بها الرؤى

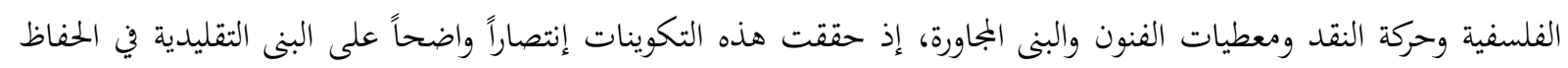

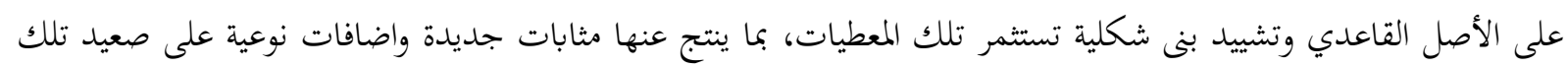

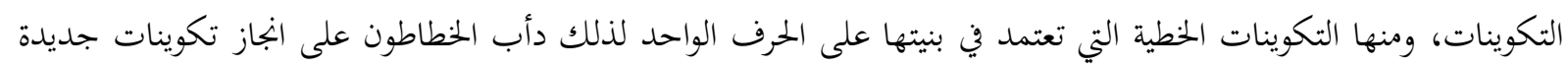

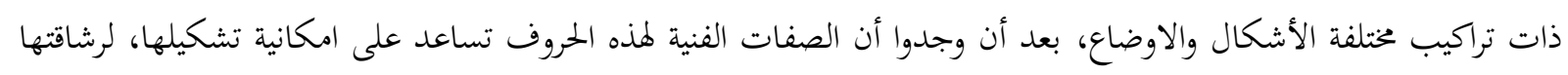

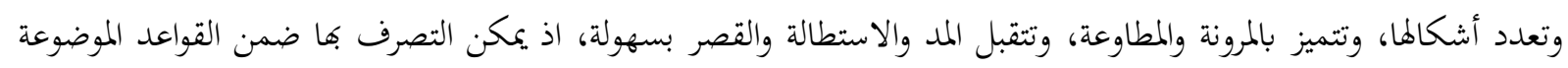

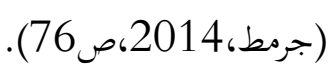

فنرى اللوحات الخطية والتراكيب متجددة ومتنوعة كلاً وامكانية الخطاط الفنية والتنفيذية، ضمن القواعد الخطية الثابتة

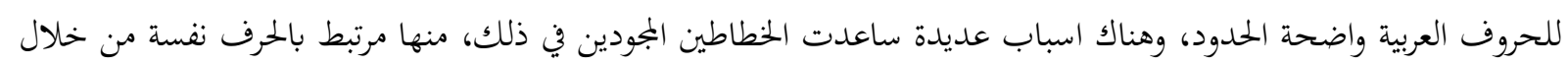

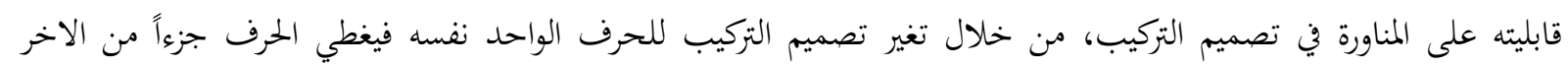

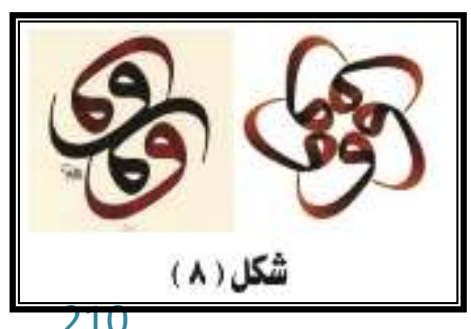

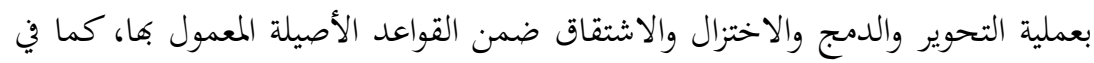
الشكل (8) 
وامتلاكه أكثر من صورة لرسم الحرف الواحد من خلال التداخل والتراكب ضمن قواعد التأصيل، محققاً الزخرفية الحروفية

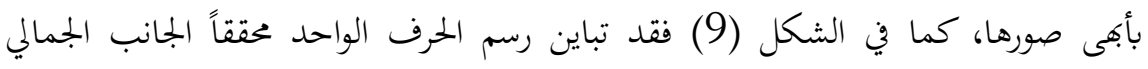

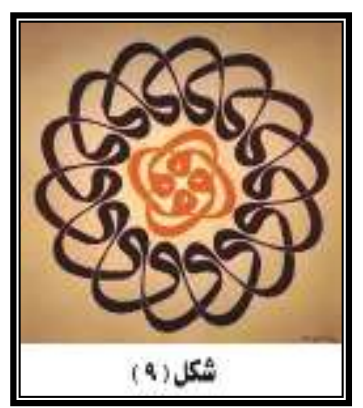

$$
\text { والزخريف في نفس التكوين. }
$$

وغيرها من المواصفات التي ساعدت على تطور تصاميم التراكيب الخطية على مر

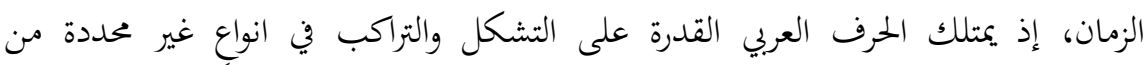

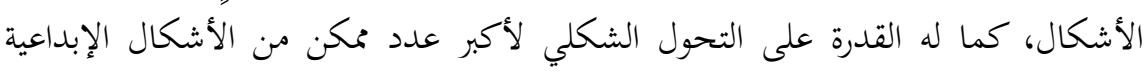

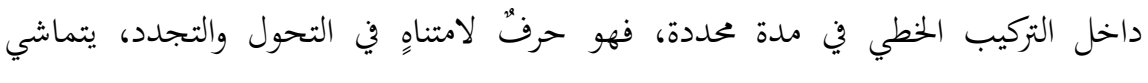
ومختلف التراكيب الفنية في الخط العربي.

وقد شهدت الساحة الفنية تكوينات خطية ذات ميول ابتكارية افرزت لنا قيماً جماليةً مضافة تتسم بالحركة والجدة والأصالة ولا تخضع للتقنين الذي يعتمد القواعد الثابتة، عكست مرونة وطلاقة واسعة في القدرة على التشكل والثنوع والإبداع لتنظيم

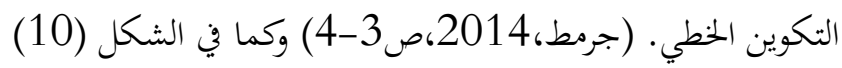

وهناك ما هو مرتبط بالخطاط المجود نفسه الذي يمتلك صفات الإبداع التي ساعدته على التجديد وهو الميدان الاوسع في ذلك، فالمبدع يمتلك صفات الإبداع وهي الأصالة والطلاقة والمرونة "وما اظهره الخطاط من قدرات إبداعية وطاقات فنية متميزة في

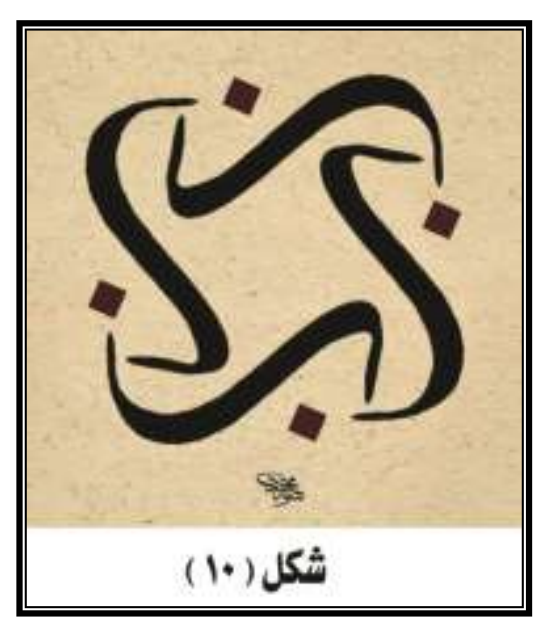
صياغة الحرف العربي وإظهاره بالمستوى اللائق الذي ميز الحرف العربي عن سواه

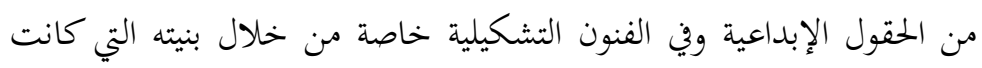

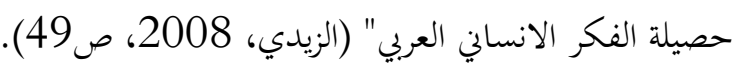
فهو ينظر إلى فن الخط العربي نظرة تشكيلية فنية مرنة غير جامدة من

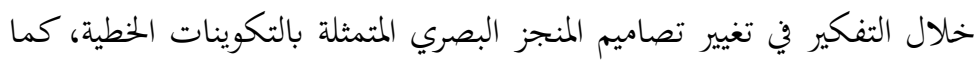

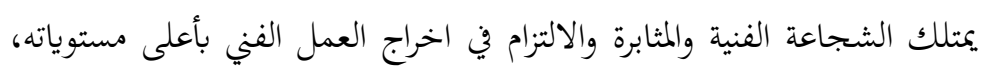

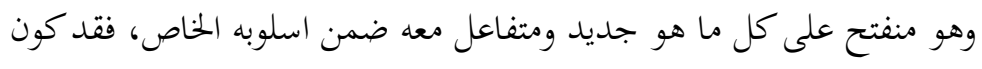

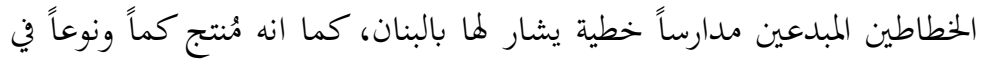
مجال اختصاصه ضمن أطر التجديد ومواكبته.

الدراسات السابقة

بعد الإطلاع على أدبيات التخصص واستقراء ومتابعة الرسائل والأطاريح الجامعية خلال الدراسة الاستطلاعية للمكتبة

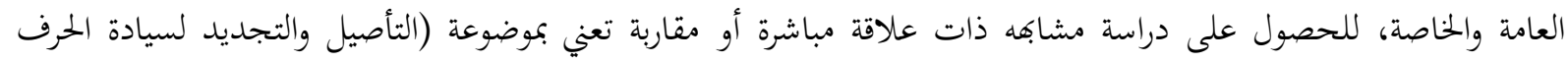

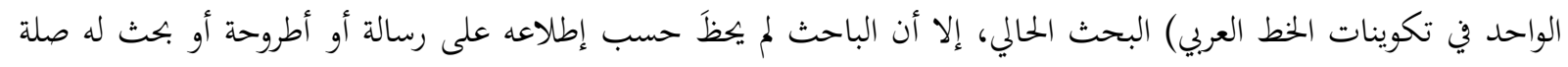
مباشرة بالموضوعة الحالية.

مؤشرات الإطار النظري 1. إن التكوينات الخطية ذات الحرف الواحد، تراكيب جمالية تخلو على الأغلب من الجانب القرائي الوظيفي وعليه اتسمت بالليونة. 2. ساعدت مطاوعة الحرف العربي في تنوع أشكال التكوينات ومتغيراتما البنيوية ضمن رؤية الخطاط جمالية. 


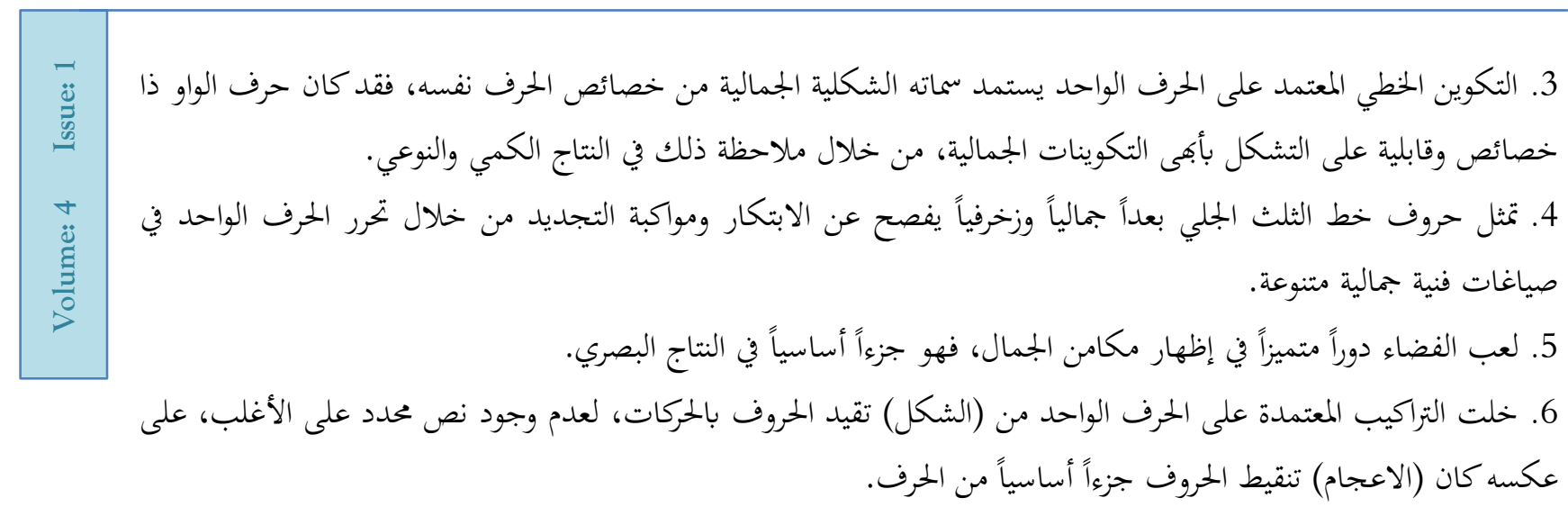


(الفصل الثالث)

\section{مجتمع البحث:}

شمل مجتمع البحث النماذج الخطية المنفذة بتكوينات ذات سيادة لحرفٍ واحٍٍ وبلغ مجموع النماذج غير المتكرة (20)

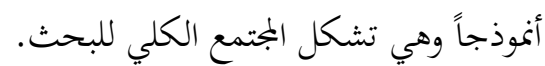

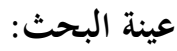
إعتمد الباحث في إختيار عينته على الانتقاء القصدي، وفقا للتشابه في تنفيذ بعض أشكال تكوينات الحرف الواحد، وطريقة توزيعها ضمن المجتمع الكلي للبحث، إذ بلغ عدد العيينات المنتقاة (2) عيينات وهي النسبة العلمية للبحث مستثني المتشابه منها.

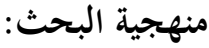

أتبع الباحث المنهج الوصفي للعينة كونه الأنسب مع هدف البحث الحالي.

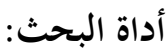

لغرض تحقيق هدف البحث الحالي، قام الباحث بتحديد المرتكزات الأساسية لتكوينات الحرف الواحد في استمارة ضمن

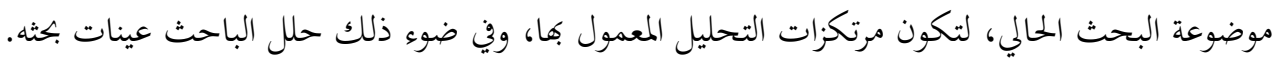

تحليل العينة

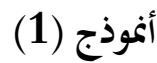

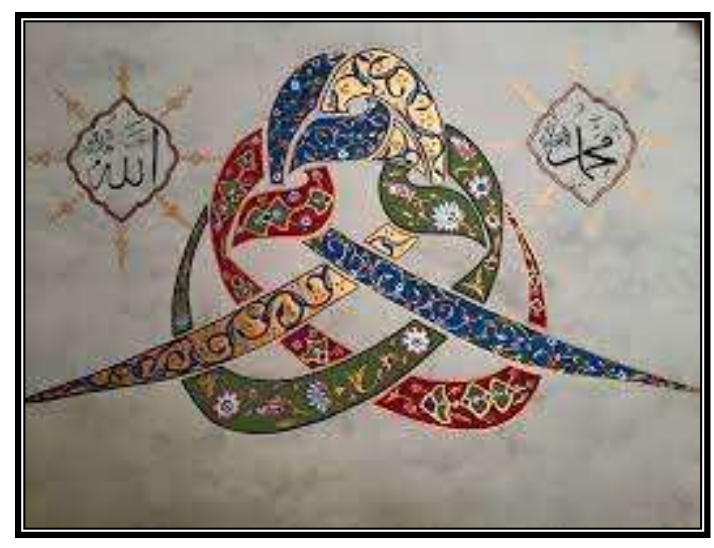

الوصف العام: تكوين خطي كتب بخط الثلث الجلي، ذو تنظيم

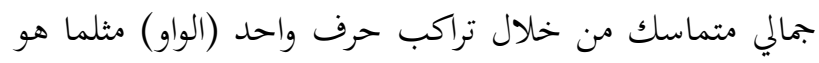

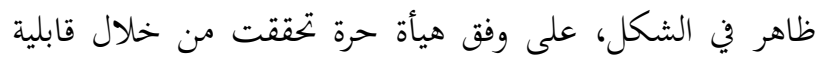
حرف الواو على التنوع،وفق تصور إبداعي دون نص قائي معين.

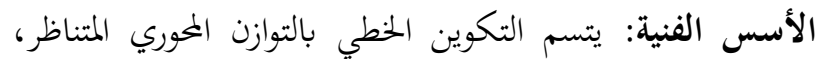

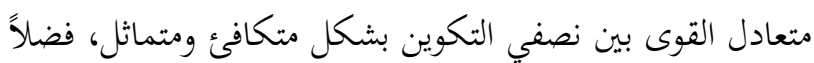

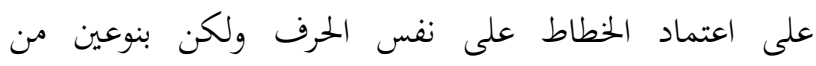

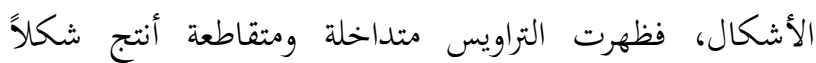

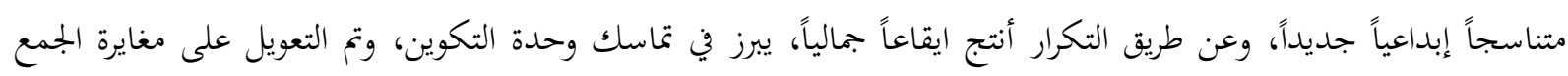

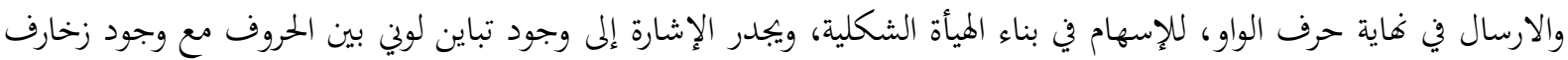

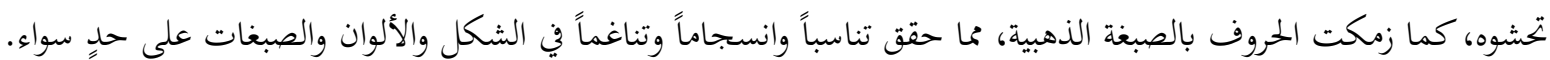
خصائص التكوين: لقد اظهر الخطاط مقدرته في المعالجات التصميمية في التجديد ضمن قواعد الأصالة، في توزيع حرف الواو

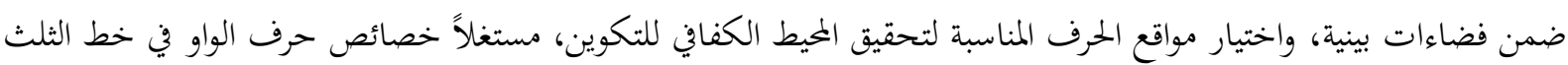


الجلي، في المرونة والمطاوعة وتنوع رسم شكل الحرف الواحد، إضافة إلى اعتماده التعاكس المرآي، مما اكسب التكوين شكلاً

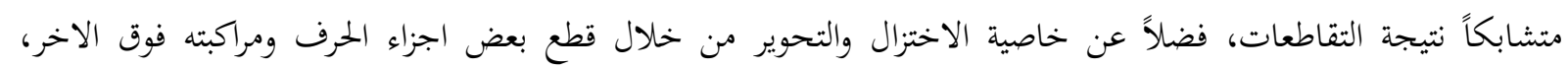
واستغلال تنوع الألوان لابراز ذلك.

دور الأصالة في خط الحرف: عمد الخطاط الالتزام بالقاعدة الخطية المعمول بها ومراعاة الاصول الخطية الصحيحة.

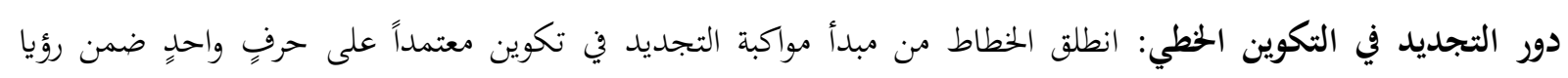
تصميمية منفتحة على الحاضر، ضمن مرجعيات فنية أصيلة.

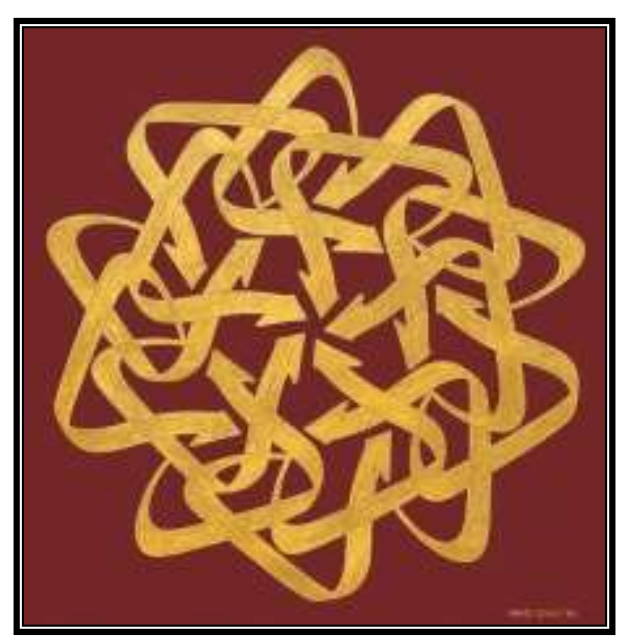

(2) (2) (2) (2)

- الوصف العام: تكوين خطي كتب بخط الثلث الجلي، ذو تنظيم جمالي متماسك من خلال تراكب حرف واحد (الدال) خلا من الاضافات الأخرى، على وفق هيأة دائرية غير منتظمة تحققت من خلال حنال قابلية حرف الدال على التشابك، محقاً شكلاً جمالياً خالي من الوظيفة القرائية.

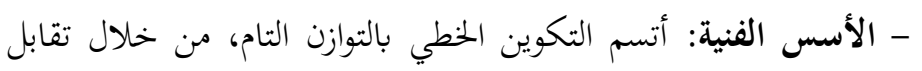

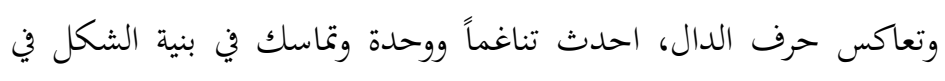
التكوين، مستغلاً شكل حرف الدال في خط الثلث الجلي، وقابليته على ونى

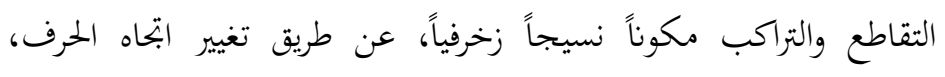

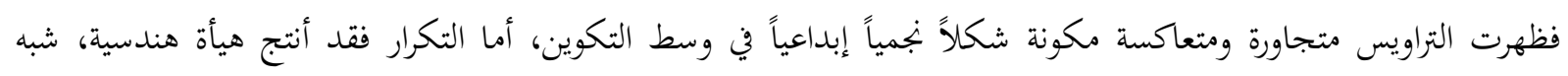
دائرية، كما عزز تكرار رسم الحرف الواحد نفسه احداث الترابط والانسجام من خلال التشابه في رسم الحرف المكرر واشغاله مساحياً ومعالجة التكوين تصميمياً.

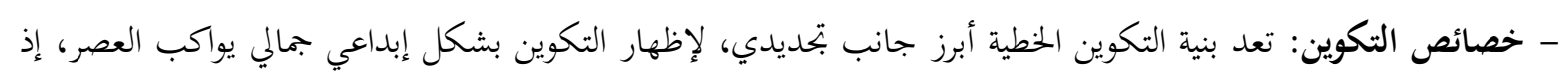

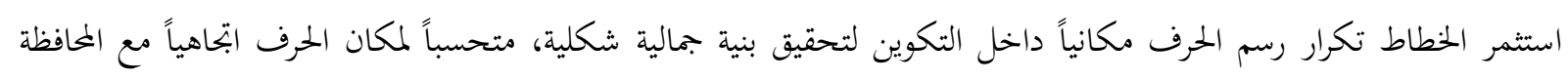
على الخميط الكفافي للتكوين، مستغلاً الفضاءات الضمنية للحرف بطريقة فنية مدروسة تدل على المهارة في معالجة التكوين.

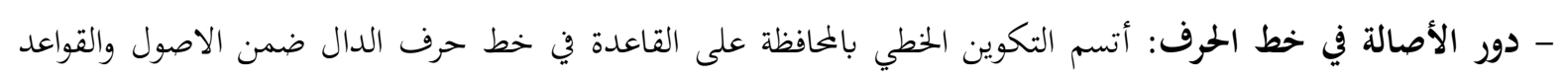
المعمول بها.

- دور التجديد في التكوين الخطي: ظهر التكوين الخطي بشكل تجديدي معاصر معتمداً على حرف الدال ضمن التوجه التصميمي ذو التجديد والابتكار. 
1. الاستمار الواعي لمفاهيم التركيب والتصميم في تراكيب الحرف الواحد الذي حقق الجانب الجمالي والإبداعي وكما في العينتين

2. المغايرة للسياق النمطي التقليدي واحدة من مظاهر التراكيب المعتمدة على حرفاً واحداً في الخطط العربي وكما في العينة (2).

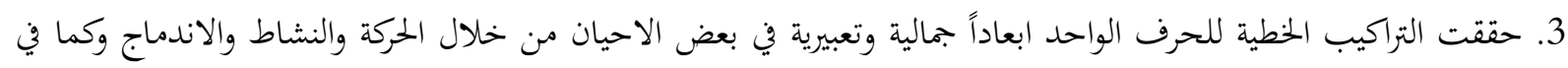

4. ظهر التوازن الجمالي والرتابة في أغلب التكوينات المعتمدة على الحرف الواحد وكما في العينة (1).

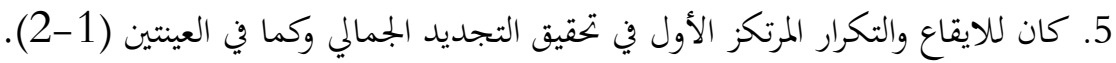

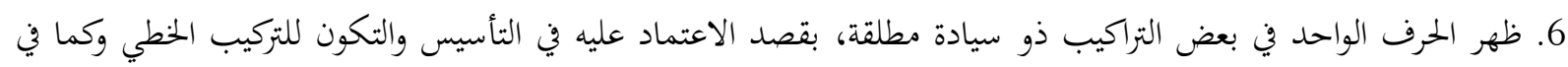

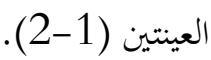
7. التناظر والتقابل له الحصة الاكبر في تكوينات الحرف الواحد في الخط العربي زكما في العينتين (1-2).

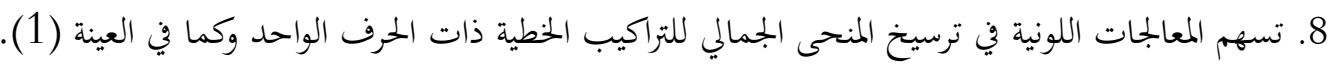

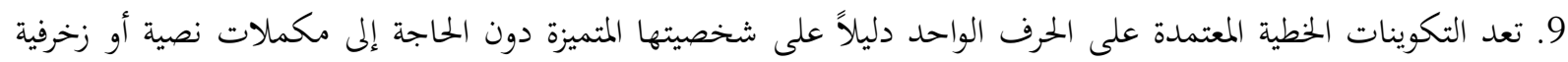
وكما العينتين (1-2) 10. حقق الحرف الواحد شكلاً زخرفياً نتيجة الايقاع المتحقق من التكرار، وعليه اكتفى ذاتياً عن الزخارف النباتية أو الهندسية أو غيرها وكما في العينة (2). الاستنتاجات

1. يككن لمفاهيم التركيب والتصميم ان تكون المرتكز الذي يعول عليه في تراكيب الحرف الواحد.

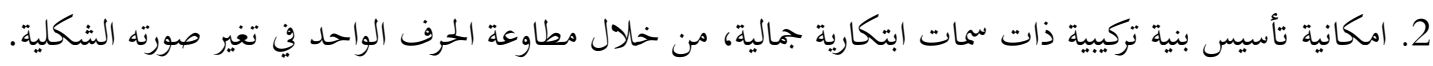

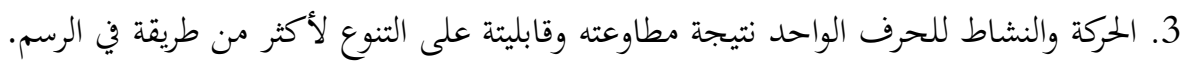

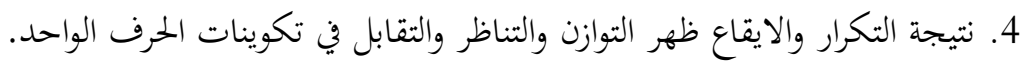

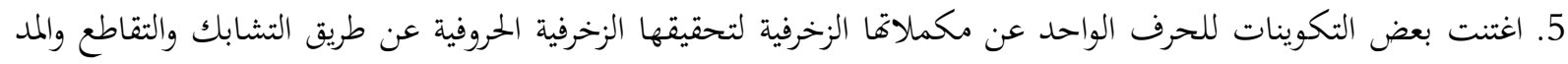
وغيرها.

1. الافادة من المغايرة في تراكيب الخط العربي لمواكبة المدراس الفنية الحديثة، بوصفه مرتكز لتطوير فن الخط العربي والمزاوجة بين الأصالة والتجديد. 2. التركيز على التأصيل في رسم الحرف ضمن القواعد الخطية، ومعرفة المرتكزات الفنية والتصمية للتجديد ضمن رؤى مدروسة. 2- المرتكزات الفنية للتجديد في تكوينات الخط العربي ضمن رؤية حداثوية. 


\section{المصادر}

(ابو ملحم،علي،1990)، نحو رؤية جديدة إلى فلسفة الفن،ط1، المؤسسة الجامعية للدراسات والنشر والتوزيع،بيروت،لبنان.

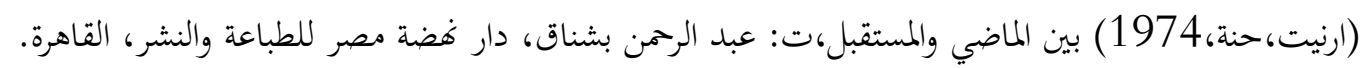

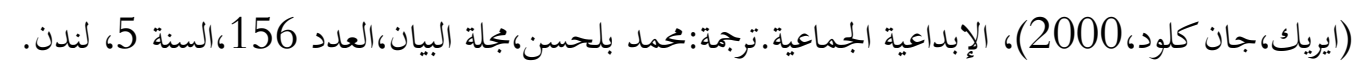
(جرمط،حسين علي،)2014، التحول من الثبات التقليدي إلى المفاهيمي في بنية تكوينات الخط العربي، كلية الفنون الجميلة،

$$
\text { جامعة بغداد، (اطروحة دكتوراه منشورة) }
$$

(حسن،حسن طه حسن،2002)،التحوير كخاصية فنية في الخط العربي وكمدخل لإثراء التصاميم الزخرفية،، كلية التربية، جامعة

$$
\text { طنطا، ( رسالة ماجستير غير منشورة) }
$$

(حنفي،حسن، (حن)، 1987، حنفي، حسن، التراث والتجديد (موقفنا من التراث القديم)، القاهرة، مكتبة الانجلو المصرية.

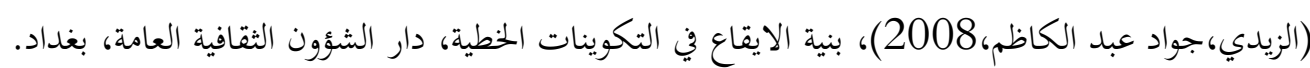

(روبرت،سكوت جيلام،1980)، 1. أسس التصميم. ترجمة محمد محمود يوسف , دار غضة مصر للطبع والنشر ,القاهرة.

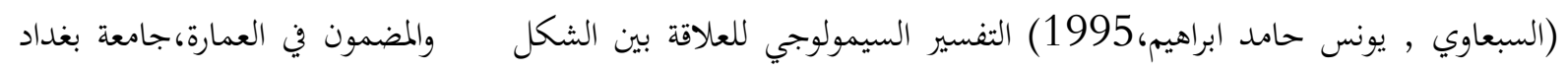

$$
\text { (رسالة ماجستير غير منشورة). }
$$

(السعدي،علي عطية موسى، 2010)،الثابت والمتحول في الفن المصري القديم، كلية الفنون الجميلة، جامعة بابل، (اطروحة

$$
\text { دكتوراه غير منشورة). }
$$

(الكناني , محمد جلوب جبر،2004)،حدس الانجاز في البنية الإبداعية بين العلم والفن. قسم الفنون التشكيلية , كلية الفنون

$$
\text { الجميلة , جامعة بغداد، (أطروحة دكتوراه غير منشورة). }
$$

(لفتة،حمد سعدي،2000)،أنموذج تدريس لإستقصاء خصائص المدرسة الفنية الحديثة. قسم التربية الفنية , كلية الفنون الجميلة

$$
\text { , جامعة بغداد، (أطروحة دكتوراه غير منشورة). }
$$

(فرمان،عدي ناظم،2004)، الخصائص الفنية في خط الثلث في المدرسة البغدادية الخطاط هاشم البغدادي أنموذجا. قسم الخطاد العربي والزخرفة , كلية الفنون الجميلة , جامعة بغداد , (رسالة ماجستير غير منشورة). 